\title{
Evaluasi Sistem Drainase Di Kecamatan Rawalumbu Kota Bekasi
}

\author{
Josua Parmonangan Sinaga ${ }^{1}$, Nico Halomoan ${ }^{2}$ \\ ${ }^{1,2}$ Teknik Lingkungan, Fakultas Teknik Sipil dan Perencanaan, Institut Teknologi Nasional Bandung \\ Jl. PKHH. Mustofa No.23 Bandung, 40124, Indonesia \\ *Koresponden email: josuaasinaga@gmail.com, nicohalomoan@itenas.ac.id
}

Diterima: 25 Desember 2021

Disetujui: 20 Januari 2022

\begin{abstract}
Rawalumbu District has 8 locations of puddle around the area, i.e. Sepanjang Jaya RW 4, Cut Meutia Street, Bumi Bekasi Baru Utara, Pondok Hijau Permai, Pondok Hijau Permai 2, Narogong Jembatan 0 Housing Area, Rawalumbu Housing Area, and across of Trisakti University. There is some reasons why this puddle happened, such as shallow happened in drainage channels, some area doesn't have drainage channels, wastes stuck in drainage channels, and elevation of some streets lower than drainage channels. The purpose of this research is for evaluates the problem that occur in drainage channels that spread around Rawalumbu District, so puddle doesn't happen again. This thesis method uses quantitative analysis, when analyzing the existing problems. According to the evaluation result, there is 2.206 channels that overflow and 91 channels that working normally. There is some methods to reduce puddle such as: changing channels that had problems and digging some clay in drainage channels. Sustainable drainage system in this research is planned for controlling the puddle with the help of infiltration wells, there is 34.587 infiltration wells that planned in this research.
\end{abstract}

Keywords: Rawalumbu District, puddle, drainage system, eco drainage, infiltration wells

\begin{abstract}
Abstrak
Kecamatan Rawalumbu memiliki 8 lokasi genangan, yaitu di Sepanjang Jaya RW 4, Jalan Cut Meutia, Bumi Bekasi Baru Utara, Pondok Hijau Permai, Pondok Hijau Permai 2, Perumahan Narogong Jembatan 0, Perumahan Rawalumbu, dan Depan Trisakti. Penyebab terjadinya genangan ini yaitu pendangkalan di saluran drainase, beberapa titik yang tidak memiliki saluran drainase, terdapatnya beberapa sampah di saluran drainase, dan elevasi jalan yang lebih rendah dari saluran drainase. Tujuan dari penelitian ini adalah untuk melakukan evaluasi terhadap permasalahan saluran drainase di Kecamatan Rawalumbu, sehingga tidak ada lagi genangan. Metode penelitian ini menggunakan analisis kuantitatif, saat menganalisis permasalahan yang ada. Riset menggunakan skala prioritas genangan, dari 8 lokasi genangan yang ada, dipilih 6 lokasi. Berdasarkan hasil evaluasi terdapat 2.206 saluran yang meluap dan 91 saluran yang aman. Terdapat beberapa cara yang dilakukan untuk mengurangi genangan, yaitu mengubah saluran eksisting dan melakukan pengurukan. Drainase berwawasan lingkungan juga turut direncanakan untuk pengendalian genangan menggunakan sumur resapan, dimana akan ada 34.587 total unit sumur resapan.

Kata Kunci: Kecamatan Rawalumbu, genangan, sistem drainase, drainase berwawasan lingkungan, sumur resapan
\end{abstract}

\section{Pendahuluan}

Kecamatan Rawalumbu merupakan salah satu dari 12 wilayah kecamatan yang berada di wilayah Kota Bekasi. Kecamatan Rawalumbu memiliki luas daerah 16,85 km², Kecamatan Rawalumbu memiliki rencana pengembangan sistem drainase dan pengendali banjir [1]. Kecamatan Rawalumbu memiliki kondisi wilayah yang relatif datar, dengan kemiringan tanah 0-2 persen, ini menyebabkan limpasan air hujan mengalir dengan kecepatan rendah juga. Hal ini juga dipengaruhi dengan kondisi curah hujan yang cukup tinggi pada bulan April 2019 yaitu tercatat 1.349,5 mm [2]. Pada saat kondisi curah hujan yang tinggi menyebabkan saluran drainase tidak dapat menampung limpahan air hujan yang berdampak pada meningkatnya debit air yang menyebabkan terjadinya genangan air di Sepanjang Jaya RW 4, Jalan Cut Meutia, Bumi Bekasi Baru Utara Pondok Hijau Permai, Pondok Hijau Permai 2 Perumahan Narogong Jembatan 0, Perumahan Rawalumbu, dan depan Trisakti [3].

Penyebab banjir lainnya di Kecamatan Rawalumbu juga disebabkan oleh tidak berfungsinya sistem jaringan drainase untuk mengalirkan debit limpasan yang banyak. Salah satu penyebab utama banyaknya sampah yang menyumbat, yang menyebabkan volume saluran drainase tersebut berkurang. Ditambah lagi dengan kurangnya lubang buangan air genangan ke saluran eksisting dari jalan raya. Permasalahan ini yang 
akan menyebabkan timbulnya dampak negatif seperti pemukiman penduduk terendam, terhambatnya akses jalan, dan kondisi jalanan yang akan menjadi rusak. Penelitian ini mengacu pada Peraturan Daerah Kota Bekasi Nomor 13 Tahun 2011 Tentang Rencana Tata Ruang Wilayah (RTRW) Kota Bekasi Tahun 20112031, disebutkan bahwa Kecamatan Rawalumbu memiliki rencana pengembangan sistem drainase dan pengendali banjir.

Penelitian ini bertujuan untuk mengidentifikasi permasalahan sistem drainase di Kecamatan Rawalumbu Kota Bekasi, mengidentifikasi titik genangan di Kecamatan Rawalumbu Kota Bekasi, dan memberikan pilihan rancangan mengenai sistem drainase di Kecamatan Rawalumbu Kota Bekasi.

\section{Metode Penelitian}

\section{Tahapan Perencanaan}

Tahapan-tahapan yang harus dilakukan antara lain identifikasi masalah, pengumpulan data terkait kondisi eksisting daerah perencanaan, analisis data, evaluasi kondisi eksisting daerah perencanaan, detail dimensi saluran dan bangunan pelengkap sistem drainase, serta spesifikasi teknis dan rencana anggaran biaya.

\section{Lokasi Perencanaan}

Daerah perencanaan terletak di Kecamatan Rawalumbu Kota Bekasi, diperoleh lokasi prioritas genangan yang dapat dilihat pada Gambar 1.

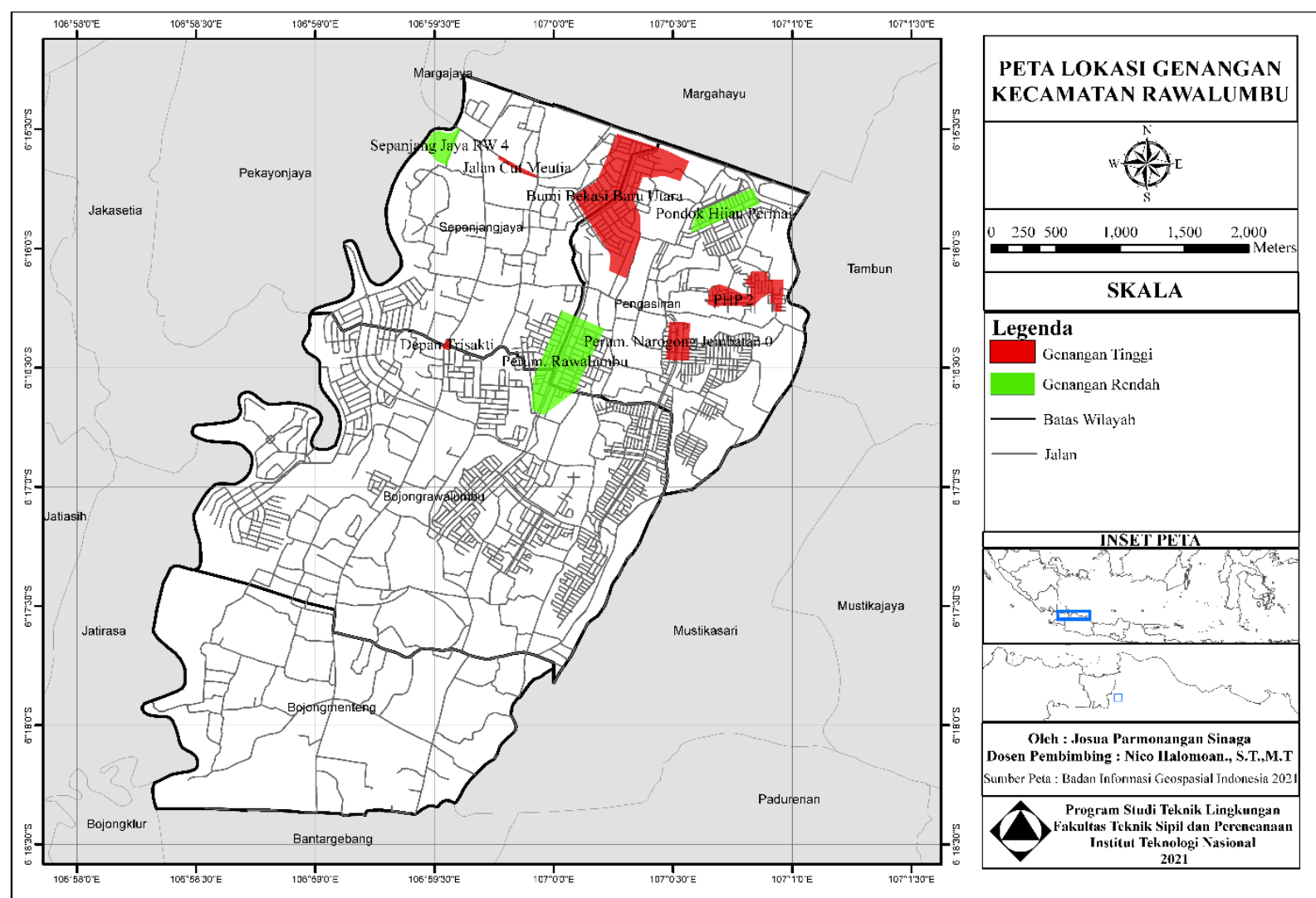

Gambar 1. Peta lokasi genangan

Sumber: DBMSDA Pemerintah Kota Bekasi (2020)

\section{Hasil dan Pembahasan Analisis Hidrologi}

Data curah hujan harian maksimum yang dikumpulkan dalam perencanaan sistem drainase adalah 30 tahun terakhir, semakin banyak data stasiun hujan yang digunakan maka tingkat keakurasian mendekati data eksisting [4]. Tahap pertama yang dilakukan dalam melakukan analisis hidrologi adalah menentukan stasiun utama menggunakan Polygon Thiessen [5]. Apabila terdapat data curah hujan yang hilang dapat menggunakan Metode Pembanding Normal atau Metode Aljabar [6]. Persamaan yang digunakan sebagai berikut :

1. Metode Pembanding Normal

Metode pembanding normal digunakan pada kondisi data curah hujan yang kehilangan datanya lebih 
dari $10 \%$. Nilai curah hujan yang hilang dapat dihitung menggunakan persamaan berikut :

$r_{x}=\frac{1}{n} \sum_{n=1}^{n} \frac{r_{n} \times R_{n}}{R_{n}}$

2. Metode Aljabar

Metode aljabar digunakan pada kondisi data curah hujan yang kehilangan datanya kurang dari $10 \%$.

Nilai curah hujan yang hilang dapat dihitung menggunakan persamaan berikut :

$R_{x}=\frac{1}{\mathrm{n}} \sum_{n=1}^{n} R n$

Dimana :

$\mathrm{n} \quad=$ Jumlah stasiun pembanding

$\mathrm{r}_{\mathrm{X}}=$ Tinggi curah hujan yang dicari

rn = Tinggi curah hujan pada tahun yang sama dengan $\mathrm{rx}_{\mathrm{X}}$, pada setiap stasiun pembanding

$\mathrm{R}_{\mathrm{X}}=$ Harga rata-rata tinggi curah hujan pada stasiun pengukur yang dihitung

$\mathrm{R}_{\mathrm{n}}$ = Harga rata-rata tinggi curah hujan pada setiap stasiun pembanding dalam kurun waktu yang sama Perhitungan persentase perbedaan curah hujan antara stasiun pembanding dan stasiun yang kehilangan data dilakukan dengan persamaan sebagai berikut :

$\Delta=\frac{S}{\mathrm{R}} \times 100 \%$

$\mathrm{S}=\sqrt{\frac{\sum(R i-R)^{2}}{n-1}}$

$\mathrm{S}=\frac{\sum R i}{n}$

Dimana :

$\Delta=$ Persen perbedaan curah hujan antara stasiun pembanding dan stasiun yang kehilangan data

$\mathrm{R}_{\mathrm{i}}=$ Nilai rata-rata curah hujan selama pengamatan tiap stasiun

$\mathrm{R}=$ Rata-rata curah hujan dari $\mathrm{n}$ jumlah stasiun pengamat

$\mathrm{n}=$ Jumlah stasiun pengamat

Berikut merupakan rekapitulasi perhitungan data curah hujan harian maksimum yang dapat dilihat pada Tabel 1.

Tabel 1. Data curah hujan harian maksimum

\begin{tabular}{|c|c|c|c|c|c|}
\hline \multirow[t]{2}{*}{ No. } & \multirow[t]{2}{*}{ Tahun Data } & \multicolumn{4}{|c|}{$\begin{array}{c}\text { Curah Hujan Harian Maksimum Stasiun Pengamatan } \\
\qquad(\mathrm{mm})\end{array}$} \\
\hline & & Halim & Balai Irigasi & Dayeuh & Bd. Cikarang \\
\hline 1. & 1991 & 92 & 97 & 95 & 95 \\
\hline 2. & 1992 & 82 & 116 & 99 & 99 \\
\hline 3. & 1993 & 95 & 110 & 103 & 103 \\
\hline 4. & 1994 & 50 & 146 & 98 & 98 \\
\hline 5. & 1995 & 137 & 78 & 108 & 108 \\
\hline 6. & 1996 & 70 & 72 & 71 & 71 \\
\hline 7. & 1997 & 75 & 91 & 83 & 83 \\
\hline 8. & 1998 & 42 & 90 & 66 & 66 \\
\hline 9. & 1999 & 42 & 108 & 75 & 75 \\
\hline 10. & 2000 & 54 & 129 & 92 & 92 \\
\hline 11. & 2001 & 93 & 112 & 103 & 103 \\
\hline 12. & 2002 & 108 & 146 & 127 & 127 \\
\hline 13. & 2003 & 72 & 126 & 99 & 99 \\
\hline 14. & 2004 & 40 & 108 & 74 & 73 \\
\hline 15. & 2005 & 97 & 116 & 102 & 92 \\
\hline 16. & 2006 & 89 & 133 & 98 & 73 \\
\hline 17. & 2007 & 218 & 215 & 176 & 96 \\
\hline 18. & 2008 & 136 & 142 & 79 & 94 \\
\hline 19. & 2009 & 140 & 170 & 117 & 178 \\
\hline 20. & 2010 & 97 & 92 & 95 & 116 \\
\hline 21. & 2011 & 90 & 151 & 60 & 95 \\
\hline 22. & 2012 & 94 & 98 & 96 & 96 \\
\hline 23. & 2013 & 161 & 260 & 211 & 211 \\
\hline 24. & 2014 & 121 & 188 & 154 & 154 \\
\hline 25. & 2015 & 125 & 147 & 136 & 136 \\
\hline 26. & 2016 & 112 & 138 & 125 & 125 \\
\hline
\end{tabular}




\begin{tabular}{cccccc}
\hline \multirow{2}{*}{ No. } & Tahun Data & \multicolumn{4}{c}{ Curah Hujan Harian Maksimum Stasiun Pengamatan } \\
\cline { 3 - 6 } & & Halim & Balai Irigasi & Dayeuh & Bd. Cikarang \\
\cline { 3 - 6 } & 2017 & 136 & 152 & 144 & 144 \\
27. & 2018 & 101 & 95 & 98 & 98 \\
28. & 2019 & 77 & 77 & 77 & 77 \\
29. & 2020 & 239 & 239 & 239 & 239 \\
30. & & &
\end{tabular}

Sumber: Hasil perhitungan, 2021

\section{Analisis Curah Hujan Harian Maksimum}

Analisa data curah hujan harian maksimum bertujuan untuk mengetahui terjadinya curah hujan harian maksimum periode ulang hujan tertentu, dengan kata lain untuk mengetahui besarnya curah hujan harian maksimum dalam suatu PUH tertentu. Untuk memperkirakan besarnya curah hujan harian maksimum yang akan terjadi selama periode ulang, maka dapat digunakan metode Gumbel, metode Log Pearson Tipe III, dan metode Iwai Kedoya. Berikut merupakan rekapitulasi perhitungan curah hujan harian maksimum yang dapat dilihat pada Tabel 2.

Tabel 2. Rekapitulasi curah hujan harian maksimum

\begin{tabular}{cccc}
\hline \multirow{2}{*}{ T(PUH) } & \multicolumn{3}{c}{ Rt (mm/24jam) } \\
\cline { 2 - 4 } & Gumbel & Log Pearson & Iway Kedoya \\
\hline 2 & $124 \pm 15$ & 121 & 129 \\
5 & $171 \pm 12$ & 162 & 168 \\
10 & $202 \pm 18$ & 191 & 191 \\
25 & $242 \pm 28$ & 231 & 217 \\
50 & $271 \pm 37$ & 263 & 234 \\
100 & $300 \pm 46$ & 297 & 251 \\
\hline
\end{tabular}

Sumber: Hasil Perhitungan, 2021

Setelah itu, dilakukan uji kecocokan menggunakan metode Chi Kuadrat untuk menguji kecocokan terhadap fungsi distribusi peluang. Berikut merupakan hasil perhitungan uji Chi Kuadrat yang dapat dilihat pada Tabel 3.

Tabel 3. Hasil perhitungan Uji Chi Kuadrat

\begin{tabular}{cccccc}
\hline No. & Distribusi & $\mathrm{X}^{2}$ Hitung & Nilai & $\mathrm{X}^{2}$ Tabel & Keterangan \\
\hline 1. & Gumbel & 2,33 & $<$ & & Diterima \\
2. & Log Person & 0,67 & $<$ & 5,44 & Diterima \\
3. & Iwai Kedoya & 11,00 & $<$ & & Tidak Diterima \\
\hline
\end{tabular}

Berdasarkan rekapitulasi hasil uji Chi Kuadrat pada Tabel 3, metode Iwai Kedoya tidak dapat diterima dikarenakan nilai $\mathrm{X}^{2}$ hitung lebih besar dibandingkan $\mathrm{X}^{2}$ tabel. Metode yang dapat diterima adalah metode Gumbel dan Log Person, jadi untuk penentuan metode terpilih menggunakan metode Log Person. Analisis Intensitas Hujan

Intensitas curah hujan adalah ketinggian curah hujan yang terjadi pada rentang waktu tertentu dimana air tersebut terkonsentrasi. Analisa intensitas curah hujan dapat diproses dari data curah hujan yang terjadi pada masa lampau. Dalam mengolah besarnya curah hujan dalam periode tertentu menjadi intensitas curah hujan dalam durasi yang berbeda-beda digunakan beberapa metode, yaitu metode Van Breen, metode Bell Tanimoto dan metode Hasper der Weduwen. Berikut merupakan rekapitulasi analisis intensitas hujan yang dapat dilihat pada Tabel 4.

Dapat dilihat pada Tabel 4 menunjukkan bahwa metode Van Breen dengan persamaan Talbot yang memiliki deviasi terkecil. Dalam perencanaan ini menggunakan hasil perhitungan intensitas hujan dari metoda Van Breen dengan persamaan Talbot. Nilai intensitas hujan terpilih dapat dilihat pada Tabel 5. 
Tabel 4. Rekapitulasi analisis intensitas hujan

\begin{tabular}{|c|c|c|c|c|c|c|c|c|c|c|}
\hline \multirow{3}{*}{ No. } & \multirow{3}{*}{ PUH } & \multirow{2}{*}{\multicolumn{3}{|c|}{ Van Breen }} & \multirow{2}{*}{\multicolumn{3}{|c|}{ Bell Tanimoto }} & \multirow{2}{*}{\multicolumn{3}{|c|}{ Hasper Dan Der Weduwen }} \\
\hline & & & & & & & & & & \\
\hline & & Talbot & Sherman & Ishiguro & Talbot & Sherman & Ishiguro & Talbot & Sherman & Ishiguro \\
\hline 1. & 2 & 0,00 & 99,99 & 96,01 & 31,82 & 21,58 & 29,68 & 86,33 & 52,33 & 300,56 \\
\hline 2. & 5 & 0,00 & 112,61 & 99,92 & 33,76 & 22,90 & 31,49 & 111,55 & 53,28 & 324,37 \\
\hline 3. & 10 & 0,00 & 119,38 & 101,38 & 35,24 & 23,90 & 32,87 & 128,07 & 68,45 & 331,72 \\
\hline 4. & 25 & 0,00 & 126,43 & 102,97 & 37,19 & 25,22 & 34,69 & 148,09 & 88,92 & 332,94 \\
\hline 5. & 50 & 0,00 & 130,84 & 104,18 & 38,66 & 26,22 & 36,06 & 162,21 & 103,87 & 328,97 \\
\hline 6. & 100 & 0,00 & 92,86 & 84,58 & 40,14 & 27,22 & 37,44 & 175,45 & 119,10 & 321,54 \\
\hline \multicolumn{2}{|c|}{ Jumlah } & 0,00 & 682,11 & 589,04 & 216,81 & 147,05 & 202,22 & 811,69 & 485,94 & 1940,10 \\
\hline
\end{tabular}

Tabel 5. Intensitas hujan dengan Metode Van Breen

\begin{tabular}{ccccccc}
\hline & \multicolumn{7}{c}{ Intensitas Curah Hujan (mm/jam) } \\
\cline { 2 - 7 } Durasi (Menit) & 2 & 5 & 10 & 25 & 50 & 100 \\
\cline { 2 - 7 } & $\mathrm{R} 1$ & $\mathrm{R} 2$ & $\mathrm{R} 3$ & $\mathrm{R} 4$ & $\mathrm{R} 5$ & $\mathrm{R} 6$ \\
\hline 5 & 177,94 & 191,62 & 200,47 & 211,64 & 220,15 & 228,89 \\
10 & 159,25 & 175,69 & 186,00 & 198,69 & 208,14 & 217,68 \\
20 & 131,61 & 150,64 & 162,54 & 177,02 & 187,65 & 198,27 \\
40 & 97,70 & 117,22 & 129,80 & 145,32 & 156,79 & 168,26 \\
60 & 77,68 & 95,94 & 108,03 & 123,25 & 134,65 & 146,14 \\
80 & 64,47 & 81,20 & 92,52 & 106,99 & 117,99 & 129,16 \\
120 & 48,11 & 62,11 & 71,88 & 84,67 & 94,58 & 104,81 \\
240 & 27,31 & 36,42 & 43,06 & 52,07 & 59,29 & 66,94 \\
\hline \multicolumn{7}{c}{ Sumber: Hasil perhitungan, 2021} \\
\end{tabular}

Sumber: Hasil perhitungan, 2021

\section{Kurva IDF}

Kurva IDF menunjukkan karakteristik wilayah curah hujan yang digunakan untuk perencanaan, pembuatan pola, dan pengoperasian proyek sumber daya air. Kurva ini terbentuk dari hubungan dari intensitas curah hujan, durasi, dan periode ulang atau frekuensi menggunakan periode ulang yang sering digunakan. Kurva IDF digunakan untuk perhitungan limpasan, dengan menggunakan intensitas hujan yang sebanding dengan waktu pengaliran curah hujan. Kurva ini menunjukkan besarnya kemungkinan terjadinya intensitas hujan yang berlaku untuk lama curah hujan sembarang [7]. Berikut merupakan kurva IDF yang dapat dilihat pada Gambar 2.

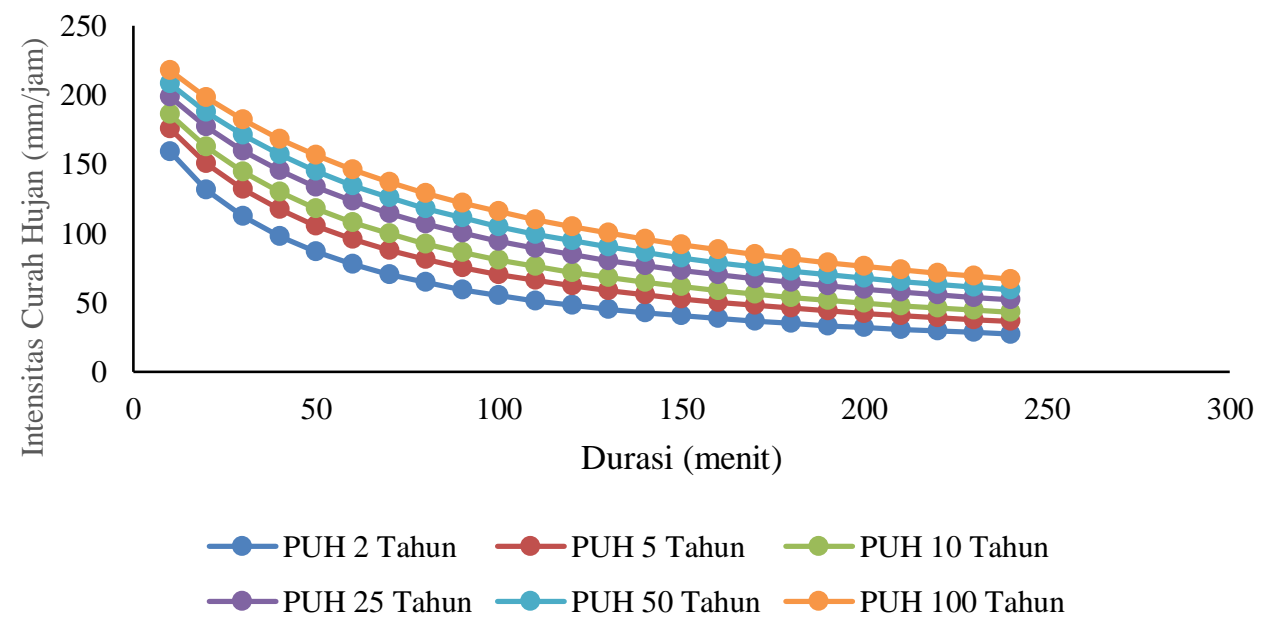

Gambar 2. Kurva IDF

Sumber: Hasil analisis (2020) 


\section{Kriteria Hidrolis \\ a. Kecepatan Aliran}

Dalam menentukan kecepatan aliran air dalam saluran dapat berdasarkan pada kecepatan minimum yang diperbolehkan agar tetap terjadi self cleansing dan kecepatan maksimum yang diperbolehkan agar konstruksi saluran tetap terjaga. Pada kecepatan minimum dan maksimum tersebut nilainya tidak tetap. Kecepatan yang umum dipakai suatu kota untuk perencanaan dimensi salurannya agar tercapai self cleansing, tetapi tidak terjadi penggerusan pada saluran adalah antara 0,6-3 m/detik [8].

\section{b. Perlengkapan Saluran}

Sarana pelengkap yang dapat menopang sistem penyaluran air hujan disebut juga sebagai perlengkapan saluran. Pada umumnya perlengkapan saluran ini terdiri dari :

\section{Street Inlet}

Street Inlet merupakan suatu lubang atau bukaan di sisi-sisi jalan yang memiliki fungsi untuk menampung dan menyalurkan limpasan air hujan yang berada di atas permukaan jalan menuju ke saluran.

\section{Bangunan Terjunan}

Bangunan terjunan dibutuhkan apabila permukaan tanah kemiringannya lebih curam dari batas kemiringan maksimum saluran. Bangunan terjunan berfungsi juga untuk menahan terjadi penggerusan pada badan saluran akibat kecepatannya dalam saluran melewati batas kecepatan maksimum.

3. Gorong-gorong

Gorong-gorong merupakan bangunan yang digunakan untuk membawa aliran air saat melewati bawah jalan atau jalan kereta api. Gorong-gorong memiliki potongan melintang yang lebih kecil daripada luas basah saluran hulu maupun hilir, untuk sebagian dari potongan melintang mungkin berada di atas muka air. Gorong-gorong memiliki fungsi sebagai saluran terbuka dengan aliran bebas [9].

\section{Evaluasi Sistem Drainase Eksisting}

Sebagian besar saluran drainase eksisting di Kecamatan Rawalumbu sudah tidak dapat menampung debit dalam saluran, sehingga menyebabkan terjadinya banjir atau genangan. Hal ini disebabkan pendangkalan di saluran drainase, beberapa titik yang tidak memiliki saluran drainase, terdapatnya beberapa sampah di saluran drainase, dan elevasi jalan yang lebih rendah dari saluran drainase. Berdasarkan hasil evaluasi tersebut dapat direncanakan perubahan dimensi pada saluran drainase di Kecamatan Rawalumbu, sesuai dengan hasil perhitungan yang dilakukan.

\section{Drainase Berwawasan Lingkungan}

Selama ini sistem drainase kebanyakan masih menggunakan konsep dimana mengalirkan air limpasan hujan ke badan air terdekat. Hal ini tidak akan membantu pengisian air tanah atau air resapan, tanpa adanya pengelolaan terlebih dahulu. Definisi konsep drainase berwawasan lingkungan adalah upaya mengelola kelebihan air dengan cara meresapkan air ke dalam tanah secara alamiah sebanyak-banyaknya atau mengalirkan ke sungai tanpa melampaui kapasitas sungai, dengan tujuan untuk mencegah terjadinya genangan dan menurunkan permukaan air [10]. Hasil dari perencanaan penerapan drainase berwawasan lingkungan akan digunakan sebagai alternatif dalam penanganan genangan di Kecamatan Rawalumbu.

\section{Sumur Resapan}

Sumur resapan adalah sumur yang dibuat untuk menampung air hujan berlebih agar meresap ke dalam tanah melalui proses infiltrasi. Sumur resapan mempunyai fungsi untuk meresapkan dan menampung air hujan yang jatuh di atas permukaan tanah [11].

\section{Kegunaan Sumur Resapan}

Beberapa fungsi sumur resapan adalah sebagai berikut [12][13] :

1. Sebagai pengendali banjir

Penggunaan sumur resapan mampu memperkecil aliran permukaan, sehingga terhindar dari penggenangan aliran permukaan secara berlebihan yang menyebabkan adanya genangan/banjir.

2. Konservasi air tanah

Sumur resapan sebagai konservasi air tanah, diharapkan air hujan lebih banyak yang diresapkan ke dalam tanah yang dimana akan menjadi air cadangan dalam tanah. Air yang tersimpan dapat dimanfaatkan melalui sumur-sumur atau mata air. Dalam hal ini mengingat semakin banyaknya tanah yang tertutup tembok, beton, aspal, dan bangunan lainnya yang tidak meresapkan air.

3. Menekan laju erosi

Dengan penurunan aliran permukaan akan membuat laju erosi menurun. Jika aliran permukaan menurun, maka tanah-tanah yang tergerus dan terhanyut akan berkurang. Efeknya aliran permukaan 
air hujan kecil dan erosi akan kecil. Oleh sebab itu adanya sumur resapan yang mampu menekan besarnya aliran permukaan berarti dapat menekan laju erosi.

\section{Perhitungan Dimensi Sumur Resapan} berikut:

Langkah-langkah dalam penentuan sumur resapan di Kecamatan Rawalumbu adalah sebagai

1. Penempatan Sumur Resapan

Penempatan sumur resapan air hujan dan resapan dan parit resapan air hujan ditempatkan pada lahan yang relatif datar dengan kemiringan maksimum $<2 \%$. Kota Bekasi memiliki kemiringan tanah antara 0-2\% . Penempatan sumur resapan akan dibangun di lokasi yang salurannya mengalami masalah di Kecamatan Rawalumbu.

2. Sumur resapan air hujan digunakan pada kedalaman air tanah $>2 \mathrm{~m}$. Kota Bekasi memiliki kedalaman muka air tanah berkisar antara 3,5-13,3 m.

3. Koefisien Permeabilitas Tanah Jenis tanah di Kecamatan Rawalumbu adalah tanah alluvial sebesar 0,036 m/jam.

4. Luas Lahan Terbangun

Luas lahan terbangun yang digunakan dalam perencanaan sumur resapan terdapat pada lokasi genangan dengan luas lahan terbangun Sepanjang jaya RW $423.419 \mathrm{~m}^{2}$, Bumi Bekasi Baru Utara $356.200 \mathrm{~m}^{2}$, Pondok Hijau Permai $198.800 \mathrm{~m}^{2}$, PHP $2113.000 \mathrm{~m}^{2}$, Perumahan Narogong Jembatan 0 $85.200 \mathrm{~m}^{2}$, dan Perumahan Rawalumbu $331.400 \mathrm{~m}^{2}$.

5. Intensitas Hujan

Intensitas hujan ditentukan menggunakan waktu durasi hujan selama 2 jam, dengan curah hujan PUH 2 tahun sebesar $121 \mathrm{~mm} / \mathrm{jam}$ yang diperoleh dari analisis hidrologi. Perhitungan intensitas hujan menggunakan persamaan berikut :

$$
\begin{aligned}
\mathrm{I} & =\frac{R}{24} \times\left(\frac{24}{t}\right)^{2 / 3} \\
& =\frac{121 \mathrm{~mm} \text { jam }}{24} \times\left(\frac{24}{2 \mathrm{jam}}\right)^{2 / 3}=26,42 \mathrm{~mm} / \mathrm{jam}
\end{aligned}
$$

6. Jumlah Sumur Resapan

Jumlah sumur resapan menggunakan asumsi pada Bumi Bekasi Baru Utara, dengan 3600 unit

7. Kedalaman Sumur Resapan Total

Dengan nilai $\mathrm{k}$ sebesar $0,0125 \mathrm{~m} / \mathrm{jam}$, sumur resapan yang dibangun direncanakan akan memiliki diameter sebesar 1 meter dan terbuat dari sumur kosong berdinding kedap air $(\omega=2)$. Kedalaman sumur resapan total dapat dihitung menggunakan persamaan 2.112 .

$\mathrm{H}=3,5 \mathrm{~m} \times$ jumlah sumur

$$
=3,5 \mathrm{~m} \text { x } 3600=12.600 \mathrm{~m}
$$

8. Debit Sumur Resapan

Nilai koefisien limpasan berdasarkan SNI-8456-2017 adalah 0,95. Perhitungan debit limpasan untuk sumur resapan pada Bumi Bekasi Baru Utara menggunakan persamaan berikut :

$\mathrm{Q}=2 \times 3,14 \times \mathrm{d} \times \mathrm{k} \times \mathrm{H}$

$$
=2 \times 3,14 \times 1 \mathrm{~m} \times 0,036 \mathrm{~m} / \mathrm{jam} \times 12.600 \mathrm{~m}=2.849 \mathrm{~m}^{3} / \mathrm{jam}
$$

Keterangan:

$\mathrm{R}=$ Curah hujan PUH 2 tahun (mm/hari), $\mathrm{I}=$ Intensitas hujan $(\mathrm{mm} / \mathrm{jam}), \mathrm{Q}=$ Debit sumur resapan $\left(\mathrm{m}^{3} / \mathrm{jam}\right), \mathrm{C}=$ Koefisien limpasan, $\mathrm{A}=$ Luas area, $\mathrm{r}=$ Radius sumur resapan, dan $\mathrm{H}=$ Kedalaman sumur.

\begin{tabular}{|c|c|c|c|c|c|c|}
\hline Lokasi & $\begin{array}{c}\mathrm{k} \\
(\mathrm{m} / \mathrm{jam})\end{array}$ & $\mathrm{A}\left(\mathrm{m}^{2}\right)$ & $\mathrm{I}(\mathrm{mm} / \mathrm{jam})$ & $\begin{array}{c}\mathrm{Q} \\
\left(\mathrm{m}^{3} / \mathrm{jam}\right)\end{array}$ & H total & $\begin{array}{c}\text { Jumlah } \\
\text { Sumur } \\
(\mathrm{H}= \\
3,5 \mathrm{~m})\end{array}$ \\
\hline Sepanjang Jaya RW 4 & 0,036 & 23.419 & 26,42 & 198 & 875 & 250 \\
\hline Bumi Bekasi Baru Utara & 0,036 & 356.200 & 26,42 & 2849 & 12600 & 3600 \\
\hline Pondok Hijau Permai & 0,036 & 198.800 & 26,42 & 1583 & 7000 & 2000 \\
\hline PHP 2 & 0,036 & 113.000 & 26,42 & 950 & 4200 & 1200 \\
\hline
\end{tabular}

Berikut merupakan rekapitulasi perhitungan sumur resapan pada Kecamatan Rawalumbu yang dapat dilihat pada Tabel 6.

Tabel 6. Rekapitulasi perhitungan sumur resapan 


\begin{tabular}{|c|c|c|c|c|c|c|}
\hline Lokasi & $\begin{array}{c}\mathrm{k} \\
(\mathrm{m} / \mathrm{jam})\end{array}$ & $\mathrm{A}\left(\mathrm{m}^{2}\right)$ & $\mathrm{I}(\mathrm{mm} / \mathrm{jam})$ & $\begin{array}{c}\mathrm{Q} \\
\left(\mathrm{m}^{3} / \mathrm{jam}\right)\end{array}$ & H total & $\begin{array}{c}\text { Jumlah } \\
\text { Sumur } \\
(\mathrm{H}= \\
3,5 \mathrm{~m})\end{array}$ \\
\hline Perumahan Narogong Jembatan 0 & 0,036 & 85.200 & 26,42 & 712 & 3150 & 900 \\
\hline Perumahan Rawalumbu & 0,036 & 331.400 & 26,42 & 2769 & 12250 & 3500 \\
\hline
\end{tabular}

Sumber: Hasil perhitungan, 2021

Berdasarkan hasil perhitungan debit limpasan dari perhitungan dimensi saluran pada lokasi Bumi Bekasi Baru Utara diperoleh sebesar 52,03 m3/s, dengan debit total sumur resapan diperoleh sebesar 0,79 $\mathrm{m}^{3} / \mathrm{s}$. Pada informasi diatas, dapat diperoleh persentase jumlah air teresapkan oleh sumur resapan di Bumi Bekasi Baru Utara dengan menggunakan persamaan berikut :

$$
\% \text { Jumlah Air Teresapkan }=\frac{Q \text { Sumur Resapan }}{Q \text { total limpasan }}=\frac{0,79 \mathrm{~m}^{3} / \mathrm{s}}{52,03 \mathrm{~m}^{3} / \mathrm{s}}=2 \%
$$

Berikut merupakan rekapitulasi perhitungan persen air yang teresap yang dapat dilihat pada Tabel 7.

Tabel 7. Rekapitulasi Perhitungan Sumur Resapan

\begin{tabular}{cccc} 
Lokasi & $\begin{array}{c}\text { Debit Limpasan } \\
\left(\mathrm{m}^{3} / \mathrm{s}\right)\end{array}$ & $\begin{array}{c}\text { Debit Sumur Resapan } \\
\left(\mathrm{m}^{3} / \mathrm{s}\right)\end{array}$ & $\begin{array}{c}\% \text { Air } \\
\text { Teresap }\end{array}$ \\
\hline Sepanjang Jaya RW 4 & 9,36 & 0,16 & $1 \%$ \\
Bumi Bekasi Baru Utara & 52,03 & 2,44 & $2 \%$ \\
Pondok Hijau Permai & 33,66 & 1,36 & $1 \%$ \\
PHP 2 & 24,98 & 0,78 & $1 \%$ \\
Perumahan Narogong & 15,33 & 0,58 & $1 \%$ \\
Jembatan 0 & 34,75 & 2,27 & $2 \%$ \\
\hline Perumahan Rawalumbu & & & \\
\hline
\end{tabular}

Sumber: Hasil perhitungan, 2021

\section{Spesifikasi Teknis dan Rencana Anggaran Biaya \\ Operasi dan Pemeliharaan}

Kegiatan operasi dan pemeliharaan diantaranya sebagai berikut [14] :

1. Kegiatan Pengamanan dan Pencegahan

Kegiatan pengamanan dan pencegahan dilakukan, untuk menjaga fungsi sistem drainase agar dapat berjalan efektif. Kegiatan ini meliputi inspeksi rutin dan larangan merusak bangunan drainase.

2. Kegiatan Perawatan

Kegiatan perawatan antara lain pembersihan vegetasi pada tebing saluran, pengurukan sedimen, dan menambal dinding saluran yang retak.

3. Kegiatan Perbaikan

Kegiatan perbaikan perlu dilakukan, jika terdapat saluran drainase yang telah rusak karena bencana alam atau kelalaian manusia.

\section{Rencana Anggaran Biaya}

Rencana anggaran biaya perencanaan saluran drainase dan bangunan pelengkapnya dihitung berdasarkan harga satuan untuk masing-masing pekerjaan baik material maupun jasa. Dalam perhitungan rencana anggaran biaya tidak lakukan pada kegiatan operasional dan pemeliharaan, hanya dilakukan untuk kegiatan konstruksi. Harga satuan upah pekerja didapatkan berdasarkan Harga Satuan Pokok Kegiatan Pemerintah Kota Bekasi Tahun 2021 [16]. Berikut merupakan rekapitulasi RAB di Kecamatan Rawalumbu yang dapat dilihat pada Tabel 8.

Tabel 8. Rekapitulasi RAB di Kecamatan Rawalumbu

\begin{tabular}{clcccc}
\hline No. & \multicolumn{1}{c}{ Uraian Pekerjaan } & Satuan & Volume & Jumlah Bahan & Harga Total \\
\hline & Saluran Sekunder & & & & \\
\cline { 2 - 5 } 1. & Galian Tanah & $\mathrm{m}^{3}$ & 65.166 & $\mathrm{Rp} 98.000,00$ & Rp6.386.268.000,00 \\
& Buangan Tanah Sisa Galian & $\mathrm{m}^{3}$ & 65.166 & $\mathrm{Rp} 355.290,51$ & Rp23.152.861.676,77 \\
\hline
\end{tabular}




\begin{tabular}{|c|c|c|c|c|c|}
\hline \multirow[t]{7}{*}{ No. } & Uraian Pekerjaan & Satuan & Volume & Jumlah Bahan & Harga Total \\
\hline & Beton Tumbuk 1:3:5 & $\mathrm{m}^{3}$ & 48.676 & Rp11.916.851,08 & Rp580.064.643.230,44 \\
\hline & Pembesian Wiremesh M10 & $\mathrm{m}^{2}$ & 5.517 & Rp120.857,25 & Rp666.769.446,32 \\
\hline & Bekisting & $\mathrm{m}^{2}$ & 237.103 & Rp112.808,30 & Rp26.747.186.701,07 \\
\hline & Pemadatan Tanah & $\mathrm{m}^{3}$ & 65.166 & Rp98.000,00 & Rp6.386.268.000,00 \\
\hline & Pembongkaran Bekisting & $\mathrm{m}^{2}$ & 237.103 & Rp16.921,25 & Rp4.012.078.005,16 \\
\hline & Pembongkaran Beton & $\mathrm{m}^{3}$ & 48.676 & Rp29.792.127,70 & Rp1.450.161.608.076,10 \\
\hline \multirow{9}{*}{2.} & Saluran Tersier & & & & \\
\hline & Galian Tanah & $\mathrm{m}^{3}$ & 87.346 & Rp98.000,00 & Rp8.559.908.000,00 \\
\hline & Buangan Tanah Sisa Galian & $\mathrm{m}^{3}$ & 87.346 & Rp355.290,51 & Rp31.033.205.291,40 \\
\hline & Pemasangan Batu Kali & $\mathrm{m}^{3}$ & 19.391 & Rp11.890.986,16 & Rp230.578.112.678,98 \\
\hline & Pembesian Wiremesh M10 & $\mathrm{m}^{2}$ & 5.656 & Rp120.857,25 & Rp683.568.604,02 \\
\hline & Bekisting & $\mathrm{m}^{2}$ & 211.858 & Rp112.808,30 & Rp23.899.341.130,71 \\
\hline & Pemadatan Tanah & $\mathrm{m}^{3}$ & 87.346 & Rp80.271,77 & Rp7.011.418.133,35 \\
\hline & Pembongkaran Bekisting & $\mathrm{m}^{2}$ & 211.858 & Rp11.280,83 & Rp2.389.934.113,07 \\
\hline & Pembongkaran Batu Kali & $\mathrm{m}^{3}$ & 19.391 & Rp29.727.465,41 & Rp576.445.281.697,44 \\
\hline \multirow{9}{*}{3.} & Gorong-gorong & & & & \\
\hline & Galian Tanah & $\mathrm{m}^{3}$ & 630 & Rp98.000,00 & Rp61.740.000,00 \\
\hline & Buangan Tanah Sisa Galian & $\mathrm{m}^{3}$ & 630 & Rp355.290,51 & Rp223.833.024,22 \\
\hline & Beton Tumbuk 1:3:5 & $\mathrm{m}^{3}$ & 305 & Rp11.916.851,08 & Rp3.634.639.579,78 \\
\hline & Pembesian Wiremesh M10 & $\mathrm{m}^{2}$ & 44 & Rp120.857,25 & Rp5.317.718,98 \\
\hline & Bekisting & $\mathrm{m}^{2}$ & 1.969 & Rp112.808,30 & Rp222.119.545,57 \\
\hline & Pemadatan Tanah & $\mathrm{m}^{3}$ & 630 & Rp80.271,77 & Rp50.571.215,90 \\
\hline & Pembongkaran Bekisting & $\mathrm{m}^{2}$ & 1.969 & Rp16.921,25 & Rp33.317.931,84 \\
\hline & Pembongkaran Beton & $\mathrm{m}^{3}$ & 305 & Rp29.792.127,70 & Rp9.086.598.949,45 \\
\hline \multirow{3}{*}{4.} & Street Inlet & & & & \\
\hline & Beton Tumbuk 1:3:5 & $\mathrm{m}^{3}$ & 219 & Rp11.916.851,08 & Rp2.609.790.386,79 \\
\hline & Pembongkaran Beton & $\mathrm{m}^{3}$ & 219 & Rp29.792.127,70 & Rp6.524.475.966,98 \\
\hline \multirow{7}{*}{5.} & Outfall & & & & \\
\hline & Galian Tanah & $\mathrm{m}^{3}$ & 8 & Rp98.000,00 & Rp784.000,00 \\
\hline & Buangan Tanah Sisa Galian & $\mathrm{m}^{3}$ & 8 & Rp355.290,51 & Rp2.842.324,12 \\
\hline & Pemasangan Batu Kali & $\mathrm{m}^{3}$ & 60 & Rp11.890.986,16 & Rp713.459.169,76 \\
\hline & Siaran & $\mathrm{m}^{2}$ & 198 & Rp425.170,87 & Rp84.183.831,33 \\
\hline & Plesteran & $\mathrm{m}^{2}$ & 198 & Rp476.271,33 & Rp94.301.722,44 \\
\hline & Pembongkaran Batu Kali & $\mathrm{m}^{3}$ & 60 & Rp29.727.465,41 & Rp1.783.647.924,39 \\
\hline Total & & & & & Rp3.003.310.076.076 \\
\hline
\end{tabular}

Sumber: Hasil perhitungan, 2021

Berdasarkan Tabel 8, total RAB yang dibutuhkan untuk melakukan evaluasi saluran drainase di Kecamatan Rawalumbu sebesar Rp 3.003.310.076.076. Sumur resapan yang direncanakan berdasarkan SNI-8456-2017. pembuatan sumur resapan yang akan direncanakan pada lokasi genangan di sepanjang Jaya RW 4 sebanyak 250 unit, Bumi Bekasi Baru Utara 3.600 unit, Pondok Hijau Permai 2.000 unit, PHP 21.200 unit, Perumahan Narogong Jembatan 0900 unit, dan Perumahan Rawalumbu 3.500 unit. Berikut merupakan RAB pembuatan sumur resapan pada lokasi genangan yang dapat dilihat pada Tabel 9. 
Tabel 9. RAB pembuatan sumur resapan pada lokasi genangan

\begin{tabular}{clcccc}
\hline No. & \multicolumn{1}{c}{ Uraian Pekerjaan } & Satuan & Volume & Jumlah Bahan & Harga Total \\
\hline $\begin{array}{l}\text { 1. } \\
\text { Pemur Resapan } \\
\text { Resapangan Sumur }\end{array}$ & unit & 11.450 & Rp11.730.221,83 & Rp134.311.039.970 \\
\hline
\end{tabular}

sumber: Hasil perhitungan, 2021

\section{Kesimpulan}

Berdasarkan hasil evaluasi dan perencanaan sistem drainase yang dilakukan dapat ditarik kesimpulan bahwa terdapat 6 titik lokasi genangan yang yang berada di Kecamatan Rawalumbu, berdasarkan hasil evaluasi skoring. Lokasi genangan tersebut berada di Sepanjang Jaya RW 4, Bumi Bekasi Baru Utara, Pondok hijau Permai, PHP 2, Perumahan Narogong Jembatan 0, Perumahan Rawalumbu. Selanjutnya, penyebab masalah tersebut, karena belum memiliki saluran drainase, penyempitan saluran drainase, terdapatnya sampah pada saluran drainase, elevasi jalan yang lebih rendah dari saluran drainase, dan terdapatnya pendangkalan pada saluran drainase. Pada evaluasi saluran drainase yang dilakukan menggunakan metode terpilih yaitu Log Person, dengan PUH 5 sebesar $162 \mathrm{~mm} / \mathrm{hari}$ dan PUH 2 sebesar $121 \mathrm{~mm} / \mathrm{hari}$.

Evaluasi saluran drainase dan perhitungannya meliputi, debit limpasan, jumlah total banyaknya saluran, dan jumlah total bangunan pelengkap. Jumlah total debit limpasan yang dihasilkan di Kecamatan Rawalumbu sebesar $2.275,72 \mathrm{~m}^{3} / \mathrm{s}$. Jumlah banyaknya saluran yang direncanakan pada drainase di Kecamatan Rawalumbu sebanyak 2.296 saluran. Jumlah bangunan pelengkap yang direncanakan di Kecamatan Rawalumbu, dengan gorong-gorong sebanyak 74 buah, street inlet sebanyak 219 buah, dan outfall sebanyak 80 buah. Oleh sebab itu, drainase yang berwawasan lingkungan dilakukan dengan membuat sumur resapan berjumlah 731 unit di Sepanjang Jaya RW 4, 11.119 unit di Bumi Bekasi Baru Utara, 6.206 unit di Pondok Hijau Permai, 3.527 unit di PHP 2, 2.660 unit di Perumahan Narogong Jembatan 0, dan 10.345 unit di Perumahan Rawalumbu. Maka anggaran biaya yang dibutuhkan untuk perencanaan sistem drainase di Kecamatan Rawalumbu sebesar Rp. 953.374.680.049 dan untuk perencanaan sumur resapan sebesar Rp. 405.713.182.485

\section{Referensi}

[1] Peraturan Daerah Kota Bekasi Nomor 13 Tahun 2011 tentang Rencanan Tata Ruang Wilayah (RTRW) Kota Bekasi Tahun 2011-2031.

[2] BPS Kecamatan Rawalumbu. 2020. Bekasi : Badan Pusat Statistik.

[3] Dinas Bina Marga Dan Sumber Daya Air (DBMSDA) Pemerintah Kota Bekasi 2021.

[4] Wesli. 2008. Drainase Perkotaan. Yogyakarta: Graha Ilmu.

[5] Suripin. 2004. Sistem Drainase Perkotaan yang Berkelanjutan. Yogyakarta : ANDI Yogyakarta.

[6] Hardjosuprapto, Masduki. 1998. Drainase Perkotaan, Volume 1. Bandung: Penerbit ITB.

[7] Melinda, N, "Perencanaan Sistem Drainase pada Daerah Aliran Sungai Cimahi di Kota Cimahi," SKRIPSI, Vol. 17, No. 2, Hal: 154-163, 2012.

[8] Peraturan Menteri Pekerjaan Umum Nomor 12 Tahun 2014 tentang Penyelenggaraan Sistem Drainase Perkotaan.

[9] Tri, Mulyono. 2017. Modul1: Perencanaan Drainase Jalan. Jakarta: Program D3 Transportasi Fakultas Teknik Universitas Negeri Jakarta.

[10] Maryono, Agus. 2003. Pembangunan, Sungai, dan Restorasi Sungai. Yogyakarta: Universitas Gajah Mada.

[11] Kusnaedi. 2011. Sumur Resapan untuk Pemukiman Perkotaan dan Pedesaan. Jakarta (ID): Penebar Swadaya.

[12] Bachtiar, Shafur. 2008. Studi Penggunaan Sumur Resapan untuk Mengurangi Masalah Genangan di DPS Amprong Kecamatan Kedungkandang Kota Malang. Malang: Jurusan Teknik Pengairan Fakultas Teknik Universitas Brawijaya.

[13] SNI-8456-2017 tentang Sumur dan Parit Resapan Air Hujan.

[14] Rencana Pembangunan Jangka Menengah Daerah (RPJMD) Kota Bekasi Tahun 2018-2023.

[15] Keputusan Wali Kota Bekasi tentang Harga Satuan Pokok Kegiatan Pemerintah Kota Bekasi Tahun Anggaran 2021. 